\title{
Evaluation of a hospital pharmacy-based pharmaceutical care services for asthma patients
}

\author{
Elkhansa ABDELHAMID, Abdelmoneim AWAD, Abdellatif GISMALLAH.
} Received (first version): 1-Oct-2007

Accepted: 4-Feb-2008

\begin{abstract}
$^{*}$
Objectives: To implement and assess hospitalbased pharmaceutical care services for patients with asthma.

Methods: A prospective, randomized, controlled study was conducted in Shaab teaching hospital, Khartoum, Sudan. Patients were allocated randomly either in the intervention group (60) or control group (40) patients. The drug therapy of asthma for the patients in the intervention group was reviewed by a trained pharmacist, and interventions were suggested to the attending physicians for the identified problems. Intervention patients received comprehensive medication counselling and asthma education every 2 weeks, while the control group received the routine medical consultation and dispensing services. The outcome measures were recorded using structured forms at baseline and monitored during a follow-up of every two weeks for 6 months in both groups. Data were analyzed using SPSS version 13 , level of significance was $p<0.05$. Results: At the end of the study period the mean reduction in frequency of acute attacks (1.91; $S D=0.18$ vs. $1.0 ; S D=0.14 ; p=0.03)$, nocturnal asthma symptoms ( $3.5 ; \mathrm{SD}=0.3$ vs. $1.1 ; \mathrm{SD}=0.2$; $p=0.02)$ and frequency of using inhaled $\beta 2$ agonists per week (19.9; $S D=2.1$ vs. $3.3 ; S D=0.3 ; p=0.01)$ were significantly greater in the intervention group compared to control. A significant mean reduction $(p=0.002)$ in the days of sickness/week was in the intervention group, while in control group there was an increase in mean days of sickness/week. The intervention group showed a significant greater improvement in the score for assessing the inhalation technique $(p<0.001)$, patient's knowledge about asthma $(p<0.001)$, and its drug-therapy $(p=0.01)$ compared with control.

Conclusion: The present findings suggest that pharmacist's intervention can have positive impact on asthma-related outcomes in patients.
\end{abstract}

Keywords: Asthma. Pharmacists. Pharmaceutical Services. Sudan.

"Elkhansa ABDELHAMID [M.Pharm. Lecturer Department of Pharmacology, Faculty of Pharmacy, University of Khartoum (Sudan).

Abdelmoneim AWAD. Assistant Professor, Department of Pharmacy Practice, Faculty of Pharmacy, Kuwait University. Safat (Kuwait).

Abdellatif GISMALLAH. MD, PhD. Senior Chest Physician, Associate Professor. Department of Internal medicine, Faculty of Medicine, Al Neelain University, (Sudan).

\section{EVALUACIÓN DE SERVICIOS DE ATENCIÓN FARMACÉUTICA EN HOSPITAL EN PACIENTES ASMÁTICOS}

\section{RESUMEN}

Objetivos: Implantar y evaluar los servicios de atención farmacéutica hospitalaria para pacientes con asma.

Métodos: Se realizó un estudio prospectivo, aleatorizado y controlado en el Hospital Universitario de Shaab, Kartum, Sudán. Los pacientes fueron asignados aleatoriamente en el grupo intervención (60) o grupo control (40). El tratamiento antiasmático de los pacientes intervención fue revisado por un farmacéutico formado, y se sugirieron a los médicos intervenciones para los problemas identificados. Los pacientes intervención recibieron consejo sobre su completa y educación sobre el asma cada 2 semanas, mientras que el grupo control recibió la consulta médica habitual y los servicios de dispensación. Para ambos grupos se registraron las medidas de resultados utilizando formularios estructurados en el inicio y durante el periodo de seguimiento cada 2 semanas durante 6 meses. Se analizaron los datos usando SPSS versión 13 y el nivel de significación fue $\mathrm{p}<0.05$.

Resultados: El final del periodo de estudio la reducción media en la frecuencia de ataques agudos $(1,91 ; \mathrm{DE}=0,18$ vs. 1,$0 ; \mathrm{DE}=0.14 ; \mathrm{p}=0,03)$, síntomas nocturnos de asma $(3,5 ; \mathrm{DE}=0.3$ vs. 1,1 ; $\mathrm{DE}=0,2 ; \mathrm{p}=0,02)$ y frecuencia de uso de inhaladores de beta2-agonistas por semana $(19,9$; $\mathrm{DE}=2,1$ vs. 3,$3 ; \mathrm{DE}=0,3 ; \mathrm{p}=0,01)$ fueron significativamente mayores en el grupo intervención contra el control. En el grupo intervención hubo una reducción media significativa $(\mathrm{p}=0.002)$ en los días de enfermedad/semana, mientras que en el grupo control hubo un aumento de los días medios. El grupo intervención mostró una mejoría significativamente mayor en la puntuación de la evaluación de la técnica inhalatoria $(\mathrm{p}<0.001)$, el conocimiento de los pacientes sobre el asma $(\mathrm{p}<0.001)$, y su farmacoterapia $/ \mathrm{p}=0.01)$ comparado con el control.

Conclusión: Los presentes hallazgos sugieren que la intervención del farmacéutico puede tener un impacto positivo en los resultados de los pacientes relacionados con el asma.

Palabras clave: Asma. Farmacéuticos. Servicios farmacéuticos. Sudán. 


\section{INTRODUCTION}

Asthma is still one of the major health problems world-wide. Although new drugs and evidencebased guidelines have been developed in recent years, there has been no major change in asthma morbidity and mortality. ${ }^{1}$ Asthma continues to be under-diagnosed and under-treated, its appropriate management requires correct diagnosis, assessment of severity, proper management including appropriate medication, patient education, and a written action plan, ongoing monitoring, appropriate follow-up, and specialty referral where appropriate. The guidelines for treatment of asthma recommend greater involvement of the patients in the management of their diseases. ${ }^{2}$ Selfmanagement of asthma is reported to reduce its incidence and improve patients' quality of life. ${ }^{3,4}$

Self-management skills should be developed through education of the patients about asthma and its appropriate treatment by health care professionals. Pharmacists can educate patients by providing information about asthma medications and by demonstrating how to use inhaled medications and peak flow meters. They can help patients to understand their asthma management plan. In addition, pharmacists can monitor medications use and refer patients with poor control of asthma to physicians for medical care. ${ }^{5}$

In our review of the literature on the evaluation of pharmaceutical care services for asthma patients, we identified numerous articles noting the significant positive impact that pharmaceutical care services have on health care management and health care costs in the long-term. In Germany, Schulz et al. conducted a study that included 173 patients enrolled from community pharmacies (101 and 63 in the intervention and control groups, respectively). Higher peak flow rates were obtained at 6 months in the intervention group, but not at 12 months. Nevertheless, inhaler technique, medication knowledge, and quality of life were greater in the intervention group at 12 months. ${ }^{1}$ A Maltese study reported that a community pharmacy-based asthma education and monitoring program had a positive impact on quality of life, peak expiratory flow, inhaler technique, compliance with therapy and number of hospitalizations at 4,8 , and 12 months post-intervention follow up. ${ }^{6}$ In Denmark, a study of community pharmacists working in collaboration with physicians reported beneficial effects on asthma symptoms, quality of life, days of sickness, knowledge and inhaler technique, but not in peak flow rates. ${ }^{7,8}$ In New Zealand, a pharmacy-based asthma study reported improvements in drug use and asthma knowledge. ${ }^{9}$ Two Finnish community pharmacy studies reported a positive impact on few outcome measures and indicated that community pharmacists can improve asthma patient's management by identifying and addressing problems in self-management of asthma. ${ }^{10,11}$

A longitudinal non-controlled intervention study was conducted in Germany involving 183 asthma patients reported a significant improvement in clinical parameters (peak flow, clinical symptoms, asthma severity), and humanistic outcomes (quality of life, self-efficacy, knowledge, adherence, inhalation technique) as a result of the provided pharmaceutical care services. ${ }^{12}$ Shaw et al. conducted a study in New Zealand to assess a community pharmacy-based pharmaceutical care service. In this study, one hundred patients were enrolled, 431 medication related problems were identified, of these, $66.1 \%$ were related to noncompliance. There were improvements in control of symptoms and peak flow readings in the majority of patients and a significant improvement in quality of life. ${ }^{13} \mathrm{~A}$ non-controlled study was conducted in Indiana to assess an asthma disease state management program that included point-of-caretesting in the form of peak flow meters. This program was developed by an independent community pharmacy. In this study, patients who completed one year in the program had a $77 \%$ decrease in hospitalization and $78 \%$ decrease in emergency department visits compared with year prior to enrollment in the program. ${ }^{14}$

In Australia, a randomized controlled study was conducted to assess the impact of a community pharmacy asthma care program on asthma control, clinical and humanistic outcomes. In this study 191 and 205 patients were recruited in the intervention and control groups, respectively. The outcome measures were recorded at baseline and 6 months later. The findings of this study reported significant improvements in the intervention group compared to the control group in relation to asthma control, adherence to preventer medication, quality of life, asthma knowledge and inhaler technique, however, there was no significant change in spirometeric values in both groups. ${ }^{15}$

These studies were conducted in developed countries and established the clinical, economic and humanistic viability of pharmaceutical care on asthma patients. However, there is lack of information regarding the implementation of pharmaceutical care services in developing countries and its value. Studies carried out in several developing countries including Sudan have shown that prescribing and dispensing practices were frequently irrational and illogical with many inappropriate prescribing practices. ${ }^{16-21}$

Pharmaceutical care practice is intended to meet a need in the health care system that has arisen due to the increase in complexity of drug therapy and the significant level of drug-related morbidity and mortality associated with drug use. ${ }^{22}$ Therefore, the introduction of pharmaceutical care is required in developing countries to aid in the resolution of medication-related problems. The existence of variations in pharmaceutical care models and practices among countries were also reported. ${ }^{23}$ The aim of this study was to implement and assess hospital-based pharmaceutical care services for patients with asthma in Sudan. 


\section{METHODS}

The study was carried out in Shaab Teaching Hospital, which is located in Khartoum State, Sudan. The study was conducted after an approval and permission of the Federal Ministry of Health. Informed participation was sought from the patients and only those who consented were included in the study. The inclusion criteria for a patient to enter the study were previous asthma diagnosis confirmed by the physicians in attendance, age 20-60 years and residence in Khartoum state. The exclusion criteria were pregnant patients, those with other respiratory conditions such as chronic obstructive pulmonary disease and emphysema, those with tuberculosis, mental disturbances, and listening or speaking problems.

This study was carried out as prospective, randomized, controlled and single-center trial during the period from April 2003 to March 2004. The sample size was determined using Java Applets for Power and Sample Size. ${ }^{24}$ A sample of 100 patients [unequal size of 60 and 40 in each group] would be required to determine a true difference of means equal to 0.71 with an $80 \%$ power and at $5 \%$ significance level. This sample size was randomly selected from those attended the emergency department or the referral clinic. Simple random sampling was used for patients' allocation either in the intervention or control group. Sixty and 40 patients were in the intervention and control groups, respectively.

Documentation and recording systems were designed specifically for this study. Data were collected via face to face structured interview of the patients by a trained pharmacist; others were collected after clinical examination of the patients, which was done by the physicians in attendance. All the parameters of the study were documented using structured forms for each patient in both groups. The intervention focused on problem solving and individual care. The drug therapy of asthma for the patients in the intervention group was reviewed by a trained pharmacist according to the British Thoracic Society guidelines due to the non-availability of upto-date local clinical guidelines, and interventions were suggested to the physicians in attendance for the identified problems. Intervention patients were educated by a trained pharmacist on their disease, non-drug therapy measures, pharmacotherapy, selfmanagement and inhalation technique every two weeks during the follow-up period. The control group received the traditional medical consultation and dispensing services. The outcome measures were recorded at baseline enrollment and monitored during a follow-up of every two weeks for 22 weeks in both groups.

The main outcome measures that were evaluated included frequency of acute attacks per week, frequency of nocturnal symptoms per week, frequency of using short acting inhaled beta2agonist per week, days of sickness per week and rate of hospitalization. These were reported by the patients at their enrollment in the study, and they were given cards to record the occurrence of each of the above mentioned measures during the previous two weeks to every follow-up. Other outcome measures that were evaluated were as follows: peak expiratory flow rate (the best of 3 measures was recorded during each follow-up visit). It was not measured on daily basis due to the nonavailability of the required number to be given to all patients; inhaler technique (the patient was observed while using the MDI for 10 steps and each correct step was given a score of 1 , the overall score was out of 10); patient knowledge about asthma (it was assessed through asking the patient [what is asthma?; what are the precipitating and aggravating factors?; and how he/she can assess the severity?] and a score of 1 was given for each correct answer, the overall score was out of 3 ); and patient knowledge about drug therapy (it was assessed through asking the patient about dose, frequency of doses, and duration of the treatment, and a score of 1 was given for each appropriate use, the overall score was out of 3 ).

Data were entered into the statistical Package for Social Sciences (SPSS, version 13.0) for statistical analysis. Prevalence was reported as percentage and $95 \%$ confidence intervals. The confidence intervals were computed using EpiCalc 2000 (CDC, USA). The outcome measures were compared between both groups at baseline, and the differences within the intervention group pre- and post-intervention and those within the control group pre- and post-intervention were compared at 2, 4, 6, $8,10,12,14,16,18,20$ and 22 weeks $^{25}$, using Mann-Whitney test for nonparametric data analysis. Statistical significance was accepted at $p<0.05$.

\section{RESULTS}

The study included 60 and 40 patients in the intervention and control groups, respectively. During the study period 12 patients of the intervention group and 10 of the control dropped out. In the intervention group, one patient died after 6 weeks from his enrollment in the study, two patients changed their residence, and others felt that they were fine and not in need to attend the follow-up. In the control group, two patients became pregnant, but the rest withdrew without obvious reasons.

In the control group, the study population enrolled was $35 \%(95 \% \mathrm{Cl}: 21.1-51.7 \%)$ males and $65 \%(\mathrm{Cl}$ : $48.3-78.9 \%$ ) females, while those in the intervention group were $48.3 \%$ (35.4-61.5\%) males and $51.7 \%$ (Cl: $38.5-64.6 \%$ ) females. The distribution of patients according to their age in the control group was $40 \%$ (20-30 years), $25 \%$ (31-40 years), $27.5 \%$ (41-50 years), $7.5 \%$ (51-60 years) and that of the intervention group was $30 \%, 43.3 \%, 21.7 \%$ and $5.0 \%$, respectively. Twenty $(50 \%, \mathrm{Cl}: 34.1-65.9 \%)$ and $46(76.7 \%, \mathrm{Cl}: 63.7-86.2 \%)$ of the patients in the control and intervention groups had been diagnosed with asthma for more than 10 years, respectively, while the remaining were asthmatic for less than 10 years. Twenty nine $(72.5 \%$, Cl: 55.9 $84.8 \%)$ and $41(68.3 \%, \mathrm{Cl}: 54.9-79.4 \%)$ of the patients in the control and intervention groups, had a family history of asthma, respectively. Table 1 shows the drug-therapy related problems that were identified in the intervention group and the 
percentage of interventions being accepted and implemented. The drug therapy was changed towards evidence-based guidelines in collaboration with the physicians in attendance.

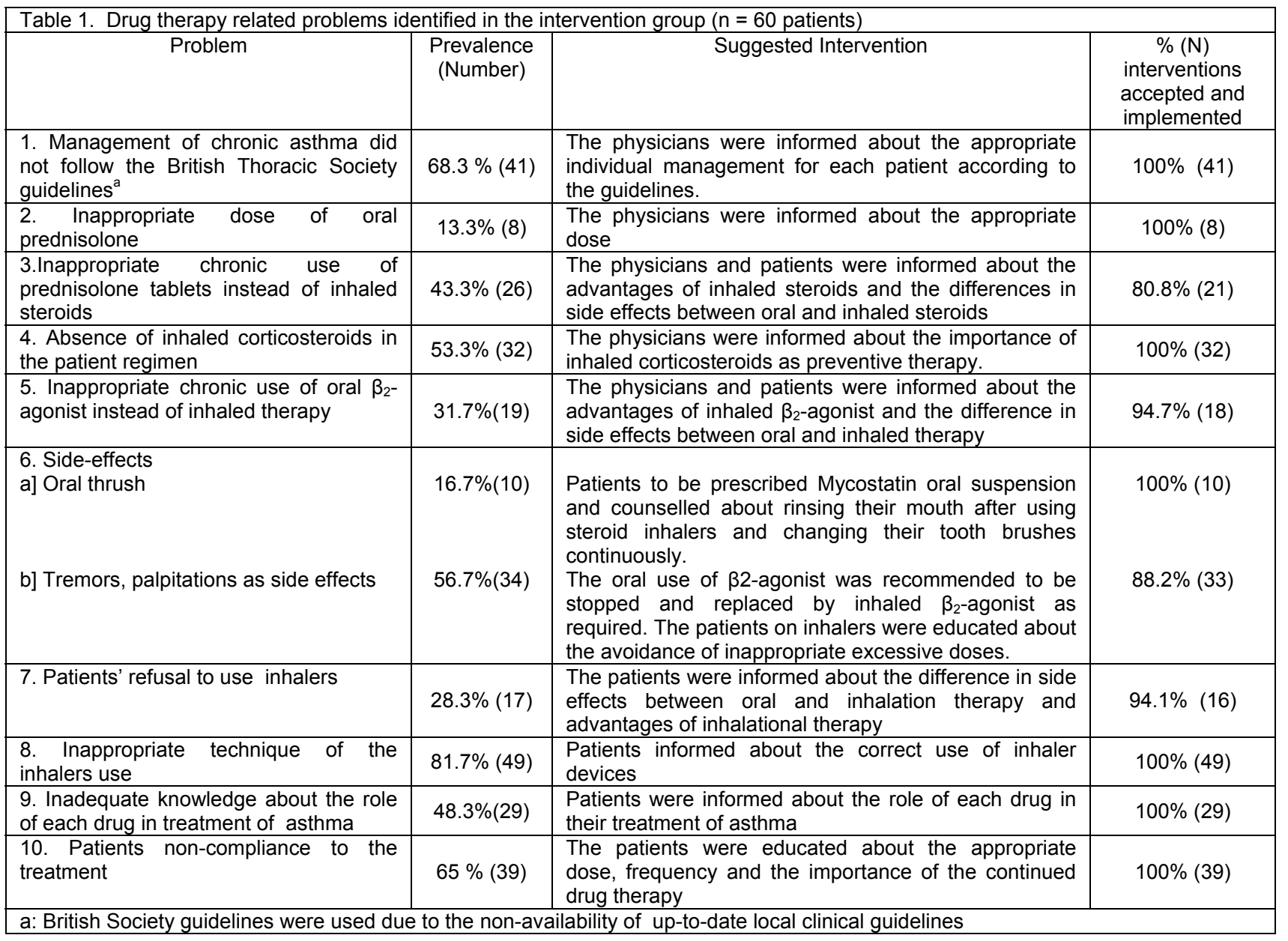

Table 2 shows that the change in the mean frequency of acute attacks per week, at the baseline enrollment; there was no significant difference $(p>0.05)$ between both groups. The reduction in mean frequency of attacks per week was significantly greater in the intervention group compared to control $(p<0.05)$. At the baseline enrollment, there was no significant difference $(p>0.05)$ between both groups in the mean frequency of the nocturnal asthma symptoms per week. The intervention group had a greater significant decrease in the mean frequency than the control group during the 20th and 22nd weeks of the follow-up $(p<0.05)$.

Table 3 shows the change in the mean frequency of using inhaled beta2-agonist per week, at the baseline enrollment. There was no significant difference $(p>0.05)$ between both groups. A significant reduction $(p<0.05)$ was achieved in the intervention group from the 6 th week to the $22 \mathrm{nd}$ week compared to control.

There was no significant difference $(p>0.05)$ between both groups in the mean days of sickness per week at the baseline enrollment. A significant reduction $(p<0.05)$ in the days of sickness was shown in the intervention group from the 2 nd week to the 22nd week, while the days of sickness were increased during the follow-up weeks in the control group. At the end of the study, a significant mean reduction $(p<0.05)$ in the days of sickness/week was noted in the intervention group $(1.4 ; S D=0.4)$, while in control group the increase was by (1.0; $S D=0.1)$. The rate of hospitalization decreased significantly $(p<0.05)$ in intervention group, while non-significantly increased $(p>0.05)$ in control compared to the rate at baseline enrolment.

At the baseline enrollment, there was no significant difference $(p>0.05)$ in the peak expiratory flow rate between both groups. The change in the peak expiratory flow rate between both groups was not statistically significant $(p>0.05)$. The intervention group patients had non-significant higher mean percentages of improvement in the peak expiratory flow rate from the 12th week until the end of the study compared to control.

Table 4 shows the change in the mean score for the technique of the inhaler use, at the baseline enrollment, there was no significant difference $(p>0.05)$ between both groups. The patients in the intervention group showed a highly significant improvement $(p<0.05)$ than those in the control group during the study period. 


\begin{tabular}{|c|c|c|c|}
\hline & $\begin{array}{l}\text { Intervention } \\
\text { group }\end{array}$ & $\begin{array}{l}\text { Control } \\
\text { group }\end{array}$ & $P$ value \\
\hline Baseline & $\begin{array}{c}2.10(1.7) \\
\mathrm{N}=60\end{array}$ & $\begin{array}{c}1.40(1.2) \\
\mathrm{N}=40\end{array}$ & 0.06 \\
\hline 2nd week & $\begin{array}{c}-1.43(0.16) \\
N=58\end{array}$ & $\begin{array}{c}-0.63(0.10) \\
N=34\end{array}$ & 0.03 \\
\hline 4th week & $\begin{array}{c}-1.83(0.16) \\
N=56\end{array}$ & $\begin{array}{c}-0.96(0.1) \\
N=33\end{array}$ & 0.03 \\
\hline 6th week & $\begin{array}{c}-1.85(0.16) \\
N=55\end{array}$ & $\begin{array}{c}-0.70(0.11) \\
\mathrm{N}=32\end{array}$ & $<0.001$ \\
\hline 8th week & $\begin{array}{c}-1.91(0.17) \\
\mathrm{N}=52\end{array}$ & $\begin{array}{c}-0.90(0.12) \\
\mathrm{N}=30\end{array}$ & 0.02 \\
\hline 10th week & $\begin{array}{c}-1.81(0.16) \\
\mathrm{N}=52\end{array}$ & $\begin{array}{c}-0.96(0.13) \\
\mathrm{N}=30\end{array}$ & 0.02 \\
\hline 12th week & $\begin{array}{c}-1.83(0.17) \\
\mathrm{N}=51\end{array}$ & $\begin{array}{c}-1.10(0.13) \\
\mathrm{N}=30\end{array}$ & 0.06 \\
\hline 14th week & $\begin{array}{c}-1.91(0.16) \\
\mathrm{N}=48\end{array}$ & $\begin{array}{c}-0.86(0.14) \\
\mathrm{N}=30\end{array}$ & 0.02 \\
\hline 16th week & $\begin{array}{c}-2.04(0.17) \\
\mathrm{N}=48\end{array}$ & $\begin{array}{c}-0.93(0.11) \\
\mathrm{N}=30\end{array}$ & 0.01 \\
\hline 18th week & $\begin{array}{c}-1.89(0.17) \\
\mathrm{N}=48\end{array}$ & $\begin{array}{c}-0.90(0.13) \\
\mathrm{N}=30\end{array}$ & 0.02 \\
\hline 20th week & $\begin{array}{c}-1.93(0.17) \\
N=48\end{array}$ & $\begin{array}{c}-0.93(0.12) \\
\mathrm{N}=30\end{array}$ & 0.01 \\
\hline 22nd week & $\begin{array}{c}-1.91(0.18) \\
N=48\end{array}$ & $\begin{array}{c}-1.00(0.14) \\
N=30\end{array}$ & 0.03 \\
\hline
\end{tabular}

\begin{tabular}{|c|c|c|c|}
\hline & $\begin{array}{l}\text { Intervention } \\
\text { group }\end{array}$ & $\begin{array}{l}\text { Control } \\
\text { group }\end{array}$ & $P$ value \\
\hline Baseline & $\begin{array}{c}26.8(2.4) \\
\mathrm{N}=60\end{array}$ & $\begin{array}{l}19.1(2.1) \\
\mathrm{N}=40\end{array}$ & 0.17 \\
\hline 2nd week & $\begin{array}{l}-9.0(0.8) \\
N=58\end{array}$ & $\begin{array}{c}-3.3(3.2) \\
N=34\end{array}$ & 0.35 \\
\hline 4th week & $\begin{array}{l}-11.5(1.4) \\
N=56\end{array}$ & $\begin{array}{c}-8.3(0.8) \\
N=33\end{array}$ & 0.46 \\
\hline 6th week & $\begin{array}{c}-16.0(1.8) \\
N=55\end{array}$ & $\begin{array}{c}-0.9(0.09) \\
\mathrm{N}=32\end{array}$ & 0.002 \\
\hline 8th week & $\begin{array}{c}-16.3(1.7) \\
\mathrm{N}=52\end{array}$ & $\begin{array}{l}-3.1(2.6) \\
\mathrm{N}=30\end{array}$ & 0.04 \\
\hline 10th week & $\begin{array}{c}-18.9(1.9) \\
N=52\end{array}$ & $\begin{array}{c}-3.8(3.7) \\
\mathrm{N}=30\end{array}$ & 0.01 \\
\hline 12th week & $\begin{array}{c}-19.0(2.0) \\
N=51\end{array}$ & $\begin{array}{c}-5.3(0.6) \\
N=30\end{array}$ & 0.02 \\
\hline 14th week & $\begin{array}{c}-19.5(1.9) \\
N=48\end{array}$ & $\begin{array}{c}-4.5(0.4) \\
N=30\end{array}$ & 0.03 \\
\hline 16th week & $\begin{array}{c}-18.9(2.0) \\
\mathrm{N}=48\end{array}$ & $\begin{array}{c}-8.9(0.9) \\
\mathrm{N}=30\end{array}$ & 0.04 \\
\hline 18th week & $\begin{array}{c}-16.8(1.8) \\
N=48\end{array}$ & $\begin{array}{c}-7.2(0.7) \\
\mathrm{N}=30\end{array}$ & 0.09 \\
\hline 20th week & $\begin{array}{c}-19.8(2.0) \\
N=48\end{array}$ & $\begin{array}{c}-6.6(0.8) \\
N=30\end{array}$ & 0.03 \\
\hline 22nd week & $\begin{array}{c}-19.9(2.1) \\
\mathrm{N}=48\end{array}$ & $\begin{array}{c}-3.3(0.3) \\
\mathrm{N}=30\end{array}$ & 0.02 \\
\hline \multicolumn{4}{|c|}{$\begin{array}{l}\text { Mean reduction is the difference for the given time-period } \\
\text { vs. baseline }\end{array}$} \\
\hline
\end{tabular}

There was no significant difference $(p>0.05)$ between both groups in the score for assessing patients' knowledge about asthma at the baseline enrollment. The improvement in asthma knowledge was significantly greater in the intervention group than in the control group $(p<0.05)$ during the followup weeks. There was no significant difference $(p>0.05)$ between both groups in the score of the patients' knowledge about appropriate use of asthma drug therapy in both groups at the baseline enrollment. The improvement was significantly greater $(p<0.05)$ in the intervention group than in the control group from the 10th week until the end of the follow-up period.

\begin{tabular}{|c|c|c|c|}
\hline & $\begin{array}{l}\text { Intervention } \\
\text { group }\end{array}$ & $\begin{array}{l}\text { Control } \\
\text { group }\end{array}$ & $P$ value \\
\hline Baseline & $\begin{array}{c}4.6(0.4) \\
\mathrm{N}=60\end{array}$ & $\begin{array}{c}6.2(0.5) \\
\mathrm{N}=40\end{array}$ & 0.03 \\
\hline 2nd week & $\begin{array}{c}+1.9(0.2) \\
\mathrm{N}=58\end{array}$ & $\begin{array}{c}+0.90(0.07) \\
\mathrm{N}=34\end{array}$ & 0.04 \\
\hline 4th week & $\begin{array}{c}+3.1(0.3) \\
\mathrm{N}=56\end{array}$ & $\begin{array}{c}+0.73(0.06) \\
N=33\end{array}$ & $<0.001$ \\
\hline 6th week & $\begin{array}{c}+3.6(0.4) \\
N=55\end{array}$ & $\begin{array}{c}+0.76(0.08) \\
N=32\end{array}$ & $<0.001$ \\
\hline 8th week & $\begin{array}{c}+3.8(0.4) \\
N=52\end{array}$ & $\begin{array}{c}+0.90(0.09) \\
\mathrm{N}=30\end{array}$ & $<0.001$ \\
\hline 10th week & $\begin{array}{c}+4.2(0.5) \\
N=52\end{array}$ & $\begin{array}{c}+1.03(0.17) \\
\mathrm{N}=30\end{array}$ & $<0.001$ \\
\hline 12th week & $\begin{array}{c}+4.3(0.4) \\
\mathrm{N}=51\end{array}$ & $\begin{array}{c}+1.06(0.18) \\
\mathrm{N}=30\end{array}$ & $<0.001$ \\
\hline 14th week & $\begin{array}{c}+4.5(0.6) \\
N=48\end{array}$ & $\begin{array}{c}+1.06(0.18) \\
\mathrm{N}=30\end{array}$ & $<0.001$ \\
\hline 16th week & $\begin{array}{c}+4.7(0.6) \\
\mathrm{N}=48\end{array}$ & $\begin{array}{c}+1.06(0.18) \\
\mathrm{N}=30\end{array}$ & $<0.001$ \\
\hline 18th week & $\begin{array}{c}+4.9(0.5) \\
N=48\end{array}$ & $\begin{array}{c}+1.06(0.18) \\
\mathrm{N}=30\end{array}$ & $<0.001$ \\
\hline 20th week & $\begin{array}{c}+4.9(0.8) \\
\mathrm{N}=48\end{array}$ & $\begin{array}{c}+1.06(0.18) \\
\mathrm{N}=30\end{array}$ & $<0.001$ \\
\hline 22nd week & $\begin{array}{c}+4.9(0.5) \\
\mathrm{N}=48\end{array}$ & $\begin{array}{c}+1.06(0.18) \\
N=30\end{array}$ & $<0.001$ \\
\hline
\end{tabular}

\section{DISCUSSION}

This is the first study to describe the value of implementing pharmaceutical care services for asthma patients in Sudan. Our findings show that the prescribing practices for management of asthma did not follow the recommendations of the up-todate clinical guidelines; therefore, there is a need for the availability of treatment guidelines with consensus about what constitutes appropriate and effective care for patients with asthma in Sudan. In this study, the pharmacist identified and solved drug-related problems in the intervention patients. The rates of acceptance and implementation of the pharmacist's interventions by the physicians were high. It is believed that pharmaceutical care requires a strengthening of the professional relationship between pharmacists and physicians to offer mutual beneficial partnerships in which both share responsibility for patient care. Indeed current evidence clearly shows that closer pharmacistphysician collaboration in the drug therapy management processes produces improved patient outcomes. ${ }^{26,27}$ The present findings underscore the value of collaboration between physicians and a pharmacist in a hospital practice to optimize drug therapy towards evidence-based guidelines, minimize drug-related problems and improve the quality of care for asthmatic patients.

The intervention patients had shown significant improvement on the frequency of acute attacks of asthma, reduction in the occurrence of nocturnal asthma symptoms, the use of inhaled beta2agonists, the days of sickness and rate of 
hospitalization. These results are consistent with those reported in the literature..$^{6,8,10,12,28}$ The present findings indicate the possible effective role of the pharmacist as a member of the health care team in improving outcomes of asthma patients through implementation of appropriate interventions to optimize drug therapy, and enhanced counseling and monitoring of patients.

In this study, the changes in the peak expiratory flow rate measurements were in line with the results found in other studies. ${ }^{6,7}$ The changes between both groups were not statistically significant; however, the intervention patients had higher mean percentages of improvement from the 12th week until the end of the study compared to control. Peak expiratory flow rates were measured on the followup dates and not on a daily basis by patients at home due to the non-availability of the required number to be given to all patients. Therefore, the data obtained are limited. In addition, the readings obtained in this study should be interpreted cautiously because several studies have reported the lack of a linear response to acquire an unbiased measurement of peak expiratory flow variability, and the significant inter and intra-meter variation with the increase in their use. Therefore, peak flow meters need to be calibrated regularly and their readings should be interpreted carefully in combination with spirometeric measures and clinical symptoms. $^{29}$

A highly significant improvement in the inhalation technique was achieved in the intervention patients compared to control. Previous studies also demonstrated that pharmacists can improve patients' inhalational technique. ${ }^{6-8}$ Although this is just a technical aspect of patient counseling, it is one of the prerequisites for achieving positive outcomes of asthma drug therapy. Indeed up to $81.7 \%$ of the intervention patients did not use their inhalers correctly at baseline enrollment in this study. Most of asthma medications are given by inhalation and without proper technique and optimal medication delivery; drugs will not be as effective as they could be. Thus, proper technique skills must be demonstrated to the patients, and should be checked annually or ideally every visit to reinforce good technique. Our findings therefore highlight the important role of the pharmacist through patient counseling in improving use of inhalational devices.

The intervention group showed significant improvement during the follow-up with regard to knowledge about asthma and its pharmacotherapy. Our results were in line with other previous studies. $^{1,7,12}$ The present study point out the effective role that a pharmacist can play in providing patients with deeper insights into their disease and drug therapy through individual counseling sessions. The improved knowledge is a good basis for safe and rational drug use and will help patients to gain confidence in appropriate self-management of asthma. It was shown that patients who have increased knowledge about their disease and drug therapy have better control of their asthma. ${ }^{30}$

The current results underline the positive impact of patient counseling provided by a pharmacist on a regular basis on the outcomes of drug therapy in asthma patients, and hence show that counseling is indeed a critical part of pharmaceutical care that can not be compromised. The reasons may be empowerment of the patient to take a more active role in the care process. In addition, the face-to-face education and couselling of asthmatic patients in the intervention group facilitated the individual learning needs and provided patients interaction and their involvement in decisions regarding their appropriate treatment. Thus, pharmaceutical care requires the development of a bond between the pharmacist and patient through effective communication as a pre-requisite for providing high quality patient care.

The control group demonstrated improvement in some of the main outcomes measures during the study period; this may have tended to reduce the apparent effect size of the pharmaceutical service. A number of factors could be at work here. Firstly, the identification of the drug-related problems in the intervention group and their discussion with the physicians in attendance may have changed their prescribing patterns and influenced the results. Secondly, the process of filling out the study forms and meeting at evaluation sessions during the follow-up may be an educational intervention itself.

The present study has shown that a trained pharmacist has a positive role in enhancement of effective treatment and monitoring of asthma patients, and in the provision of appropriate health care education. This is translated in patients having greater awareness of the disease and its treatment and with ability to obtain greater control of their illness. Based on these results, the introduction of pharmaceutical care is required in developing countries such as Sudan to aid in resolution of medication-related problems and improving the quality of patient care. In addition, it is anticipated that effective implementation of pharmaceutical care will reduce the bill from drug related problems, which believed to be "multibillion dollar problem". The net benefit for the American health care system due to the implementation of pharmaceutical was estimated to be approximately USD40 billion. ${ }^{31}$ Thus, the implementation of this practice in developing countries where prescribing and dispensing practices were frequently irrational and illogical is needed. The international Pharmaceutical Federation adopted the guidelines for the achievement of good pharmacy practice in developing countries, which was approved by the World Health Organization. ${ }^{32}$

\section{Study Limitation}

The follow-up period was short to reflect long-term effects of the intervention. Other limitations of this study included the subjectiveness of some of the measures, and reliance on self-documentation. Further research is needed with a larger number of patients into long-term outcomes and the pharmacoeconomical impact of pharmaceutical care. 


\section{CONCLUSIONS}

The present findings support the value of collaboration between physicians, pharmacists and patients, and suggest that pharmacist's intervention can have a positive impact on outcomes in asthma patients. Our results laid a basis for further development of pharmaceutical care practice in the hospitals of Sudan to improve the quality of care for asthmatic patients

\section{ACKNOWLEDGMENTS}

We gratefully acknowledge the physicians and nurses in Shaab teaching hospital for their support and collaboration in the conduction of this work. The data collection and analysis was conducted in Khartoum State - Sudan. Further data analysis and manuscript writing were undertaken in Faculty of pharmacy, Kuwait University. Thanks are due to Dr Ahmed El-Hashim for revising this manuscript.

\section{CONFLICT OF INTEREST}

None declared. The whole project was funded by Deutscher Akademischer Autausch Dienst (DAAD)/ Code No.A/01/20565.

\section{References}

1. Schulz M, Verheyen F, Muhlig S, Muller JM, Muhlbauer K, Knop-Schneickert E, Petermann F, Bergmann KC Pharmaceutical care services for asthma patients: a controlled intervention study. J Clin Pharmacol. 2001; 41: 668-76.

2. National Asthma Education and Prevention Program. Guidelines for the diagnosis and management of asthma, Expert Panel Report 2. Bethesda, Maryland: National Institutes of Health, National Heart, Lung, and Blood Institute, 1997.

3. Lahdensuo A, Haahtela T, Herrala J, Kava T, Kiviranta K, Kuusisto P, Perämäki E, Poussa T, Saarelainen S, Svahn T. Randomised comparison of guided self management and traditional treatment of asthma over one year. BMJ 1996 312:748-52

4. Beasley R, Cushley M, Holgate ST. A self-management plan in the treatment of adult asthma. Thorax 1989; 44:200-4.

5. Gibbs K, Small M. Asthma. In: Walker R and Clive E, eds. Clinical Pharmacy and Therapeutics.3rd ed. Churchill Livingstone, 375-398, 2003.

6. Cordina M, McElany JC, Hughes CM. Assessment of a community Pharmacy-Based program for patients with asthma. Pharmacotherapy 2001; 21(10):1196-203.

7. Herborg H, Soendergaard B, Jorgensen $T$, Fonnesbaek L, Hepler CD, Holst H, Froekjaer B. Improving drug therapy for patients with asthma-part 2: Use of antiasthma medications. J Am Pharm Assoc (Wash). 2001; 41(4): 551-9.

8. Herborg H, Soendergaard B, Froekjaer B, Fonnesbaek L, Jorgensen T, Hepler CD, Grainger-Rousseau TJ, Ersboell BK. Improving drug therapy for patients with asthma--part 1: Patient outcomes. J Am Pharm Assoc (Wash). 2001; 41(4): 539-50.

9. Emmerton L, Shaw J, Kheir N. Asthma management by New Zealand Pharmacists: a pharmaceutical care demonstration project. J Clin Pharm Ther. 2003; 8(5):395-402.

10. Narhi U, Airaksinen M, Erlund, H. Pharmacists Solving Problems in asthma management-experiences from a one year intervention program in Finland. Int J Pharm Pract. 2002; 3:55-9.

11.. Narhi U, Airaksinen $\mathrm{M}$, Tanskanen $\mathrm{P}$, Erlund $\mathrm{H}$. Therapeutic outcomes monitoring by community pharmacists for improving clinical outcomes in asthma. J Clin Pharm Ther. 2000; 25:177-83.

12. Mangiapane S, Schulz M, Muhlig S, Ihle P, Schubert I, Waldmann H. Community Pharmacy-Based Pharmaceutical Care for Asthma Patients. Ann Pharmacother. 2005; 39(11): 1817-22 .

13. Shaw JP, Emmerton L, Kheir NA, Barron PA, Becket G, Smith NA. Pharmaceutical care of asthma patients in a New Zealand community pharmacy setting. Pharm J.. Available at URL: http://www.pjonline.com/Editorial/20000916/practiceresearch/r24.html

14. Rupp MT, McCallian DJ, Sheth KK. Developing and marketing a community pharmacy-based asthma management program. J Am Pharm Assoc (Wash). 1997;37(6):694-9.

15. Armour C, Bosnic-Anticevich S, Brillant M, Burton D, Emmerton L, Krass I, Sainin B, Smith L, Stewart K. Pharmacy Asthma Care Program (PCAP) improves outcomes for patients in the community. Thorax 2007;62:496-502.

16. Hogerzeil HV, Bimo, Ross-Degnan D, Laing RO, Ofori-Adjei D, Santoso B, Azad Chowdhury AK, Das AM, Kafle KK, Mabadeje AF, et al. Field tests for rational drug use in twelve developing countries. Lancet. 1993;342(8884):1408-10

17. Calva JJ, Sifuentes-Osornio J, Ceron C. Antimicrobial resistance in fecal flora: Longitudinal community-based surveillance of children from urban Mexico. Antimicrob Agents Chemother 1996; 40:1699-702.

18. Quick JD, Hogerzeil HV, Velasquez G, Rago L. Twenty-five years of Essentials medicines. Bull World Health Organ. 2002;80(11):913-4

19. Awad Al, Eltayeb IB, Matowe L, Thalib L. Self medication with Antibiotics and Antimalarials in the community of Khartoum State, Sudan. JPPS 2005;8(2):326-31.

20. Eltayeb IB, Awad AI, Mohamed-Salih MS, Daffa-Alla MA, Ahmed MB, Ogail MA, Matowe L. Changing the prescribing patterns of sexually transmitted infections in the White Nile Region of Sudan. Sex Transm Infect. 2005;81(5):426-7.

21. Awad Al, Eltayeb IB, Baraka OZ. Changing antibiotics prescribing practices in health centers of Khartoum State, Sudan. Eur J Clin Pharmacol. 2006;62(2):135-42.

22. Berenguer B, La Cassa C, de la matta MJ, Martin-Calero MJ. Pharmaceutical care: past, present and future. Curr Pharm Des. 2004;10(31):3931-46.

23. Farris KB, Fernandez-Llimos F, Benrimoj SI. Pharmaceutical care in community pharmacies: Practice and research from around the world. Ann Pharmacother. 2005;39:539-41. 
24. Lenth RV. Java Applets for Power and Sample Size [Computer software]. Available at URL: http://www.stat.uiowa.edu/ rlenth/Power

25. Grimshaw JM, Thomas RE, MacLennan G, Fraser C, Ramsay CR, Vale L, Whitty P, Eccles MP, Matowe L, Shirran L, Wensing M, Dijkstra R, Donaldson C. Effectiveness and efficiency of guideline dissemination and implementation strategies. Health Technol Assess. 2004; 8(6):iii-iv,1-72.

26. Gattis WA, Hasselblad V, Whellan DJ, O'Connor CM. Reduction in heart failure events by the addition of a clinical pharmacist to the heart failure management team: results of the Pharmacist in Heart Failure Assessment Recommendation and Monitoring (PHARM) Study. Arch Intern Med. 1999;159(16):1939-45.

27. Leape LL, Cullen DJ, Clapp M, Burdick E, Demonaco HJ, Erickson JI, Bates DW. Pharmacists participation on physician rounds and adverse drug events in the intensive care unit. JAMA. 1999;282(3):267-70.

28. Boulet LP, Boutin H, Cote J, Leblanc P, Laviolette M. Evaluation of an asthma self-management education program. J Asthma 1995;32(3):199-206.

29. Nazir Z, Razaq S, Mir S, Anwar M, Al Mawlawi G, Sajad M, ShehabA, Taylor RS. Revisiting the accuracy of peak flow meters: a double-blind study using formal methods of agreement. Respir Med. 2005;99(5):592-5.

30. Sibbald B, White P, Pharoah C, Freeling P, Anderson HR. Relationship between psychosocial factors and asthma morbidity. Fam Pract. 1998;5:12-7.

31. Johnson JA, Bootman JL. Drug related morbidity and mortality and the economic impact of pharmaceutical care. Am J Health-syst Pharm. 1997;54:554-8.

32. International Pharmaceutical Federation. Good pharmacy practice (GGP) in developing countries: Recommendations for stepwise implementation. Available at URL: http://213.206.88.26/www2/pdf/gpp/GPP_CPS_Report.pdf 